\title{
Effect of viscoelasticity of EVA encapsulants on photovoltaic module solder joint degradation due to thermomechanical fatigue
}

Jiang Zhu*, Michael Owen-Bellini, Daniel Montiel-Chicharro, Thomas R. Betts, Ralph Gottschalg

Centre for Renewable Energy Systems Technology, Wolfson School of Mechanical, Electrical and Manufacturing Engineering, Loughborough University, LE11 3TU, United Kingdom

*E-mail: j.zhu@1boro.ac.uk

\begin{abstract}
:
The solder joint degradation due to thermomechanical fatigue is investigated in this paper for PV mini-modules with EVA of different viscoelastic properties. The mini-modules were laminated at different curing temperatures in order to obtain EVA encapsulation with different viscoelastic properties. The influence of viscoelasticity of EVA on the thermomechanical fatigue generated on solder joint is analyzed based on a 2D finite-element model. Based on simulation of thermomechanical stresses accumulation, mini-modules with EVA cured at lower temperatures accumulated approximately 40\% more stresses during the thermal cycle testing than mini-modules with optimal cured EVA. The tested mini-modules with EVA cured at lower temperature showed greater power degradation than the optimal cured mini-modules. An apparent increase in equivalent series resistance is the primary factor the power loss. A good correlation between the accumulated thermomechanical fatigue and the increase in equivalent series resistance is demonstrated with the tested samples.
\end{abstract}




\section{Introduction}

The lifetime of photovoltaic (PV) modules is required to be 25 years or more in PV industry in order to achieve good financial return. Understanding of the PV module degradation mechanisms is one of the main issues to further improve modules lifetime. The PV module degradation is dependent on the operation environment, module design and material selection. ${ }^{1)}$ Various degradation and failure mechanisms are reported for modules under artificial ageing, ${ }^{2-4)}$ and in real operation in different climate zones, ${ }^{5-11)}$ or after different years of operating. ${ }^{12-17)} \mathrm{PV}$ module solder joint failure is a common failure mechanism that is widely observed in the field. ${ }^{18-24)}$ The rate of solder fatiguing in different environments is not fully understood as it depends on a variety of factors, such as thermomechanical properties of the various materials in a PV module as well as the detailed stress levels and the material response to these particular stress levels. ${ }^{25-28)}$

Typical PV modules are a multi-layer system of materials consisting of a front glass sheet, a polymeric backsheet, and two layers of polymeric materials in which interconnected solar cells and electrical circuitry are encapsulated. These materials exhibit different coefficients of thermal expansion (CTE) and their mechanical behaviors depend on module operating conditions such as temperature level, temperature ramping rate, temperature dwell time and etc.

Thermomechanical fatigue on solder joints is studied by controlled thermal cycling tests in this work. Changes in temperature during thermal cycles and the CTE mismatch between constrained materials impart strain, which results in stress within and at the interface of these materials. In particular, solder joints undergo cyclic movement within the EVA during thermal cycling causing permanent deformation and the initiation of cracks leading to degradation of solder bond (i.e. series resistance increase due to loss of conduction) and finally breakage due to material fatigue. The encapsulant is an important component that provides electrical insulation and mechanical protection for electrical part of the module. It is, however, not clear its role in thermomechanical fatigue generation. Its contribution to damage on the solder bonds is rarely reported as its influence is not as critical as other components'. ${ }^{29)}$ However, a study on the influence of different types of encapsulants on PV module solder joints is carried out in Ref. 30), which demonstrates distinct difference in thermomechanical behavior for different encapsulants. This work further investigates EVA, 
which is the most common encapsulant material used in PV industry, and studies the effect of EVA encapsulants of different viscoelasticity on thermomechanical fatiguing of the solder joint as well as the associated power loss. The viscoelasticity of EVA, which is temperature dependent, describes material's elastic and viscous characteristics. EVA bulk material of different viscoelastic properties responses to stresses differently under the same thermal condition.Additionally, PV laminates with EVA of different viscoelastic properties may exhibit different level of strain during cyclic thermal conditions, which lead to expansion or contraction of the laminate assembly. These cause displacement of cells and interconnect ribbons, which can introduce significantly different stresses on module solder joints as observed in this work.

This paper investigates solder joint degradation and failure due to thermomechanical fatigue and establishes a correlation between the viscoelasticity of ethylene vinyl acetate (EVA) encapsulation and the thermomechanical fatigue generated on solder joint during thermal cycle (TC) testing. A finite-element model (FEM) was developed to assess accumulation of thermomechanical stresses on solder joint under thermal cycling tests. The result of solder joint degradation is then analyzed and linked to module power degradation and the mechanism of power loss due to solder joint loss is evaluated.

\section{Experimental methods}

\subsection{Viscoelastic Properties of EVA}

Materials which exhibit both elastic and viscous properties can be described as viscoelastic. For such materials, the strain response to an applied stress is a function of temperature. In general, increasing temperature decreases elasticity, resulting in an increasingly delayed strain response to an applied stress. Viscoelasticity may be studied using dynamic mechanical analysis, whereby an oscillatory force (or stress) is applied to a sample of material and the resulting displacement (strain) is measured. The storage modulus, $G^{\prime}$, is a measure of the stored energy within a material and is representative of the elastic portion. Loss modulus, G", is a measure of the energy which is dissipated as heat during displacement and represents the viscous portion.

$$
\mathrm{G}^{\prime}=\frac{\sigma_{0}}{\varepsilon_{0}} \cos \delta
$$




$$
G^{\prime \prime}=\frac{\sigma_{0}}{\varepsilon_{0}} \sin \delta
$$

The ratio between $G$ ' and $G$ " for a viscoelastic material is known as the loss factor, $\tan \delta$, and is a measure of the dampening in the material.

$$
\tan \delta=\frac{G \prime \prime}{G \prime}
$$

The higher the loss factor, the greater the viscous portion and the energy dissipation of the material. To assess thermomechanical fatiguing, these properties need to be known. They were measured in this work for each sample over a temperature range of $-40^{\circ} \mathrm{C}$ to $100^{\circ} \mathrm{C}$ using a TA Instruments Hybrid-2 Rheometer; applying a $1 \mathrm{~Hz}$ oscillation.

\subsection{Mini-modules with EVA of different viscoelastic properties and thermal cycling test}

In order to study the effect of viscoelasticity of EVA on solder joint degradation, a number of bespoke single cell c-Si mini-modules were fabricated with different EVA consistencies. These were subjected to TC testing between $-40^{\circ} \mathrm{C}$ and $85^{\circ} \mathrm{C}$, as prescribed in the current certification standards, ${ }^{31)}$ for 1400 cycles. This is significantly longer than the standard test but will give a more realistic stress level. Their cross sectional structure is illustrated in Fig 1 . In total, 16 samples were fabricated at four different curing temperatures of $125^{\circ} \mathrm{C}, 135^{\circ} \mathrm{C}$, $145^{\circ} \mathrm{C}$ and $150^{\circ} \mathrm{C}$. Different curing temperatures result in different viscoelastic behaviour of EVA. This difference can be presented as $\tan \delta$, which is the ratio of loss modulus over storage modulus. Figure 2 plots the measured values of tan $\delta$ over the temperature range of TC test for the EVAs cured at the four conditions. At temperatures above $50^{\circ} \mathrm{C}$, the differences become bigger. This indicates that samples cured at $125^{\circ} \mathrm{C}$ exhibit more significant displacement within the module assembly than the other samples, i.e. they are more elastic. This is expected to result in higher thermomechanical fatigue on the solder bonds. 


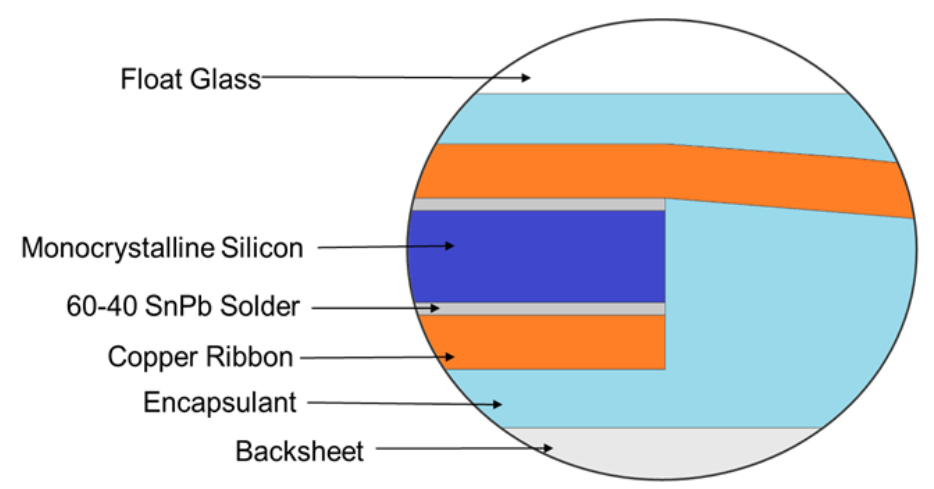

Fig. 1. Cross sectional structure of the mini-module.

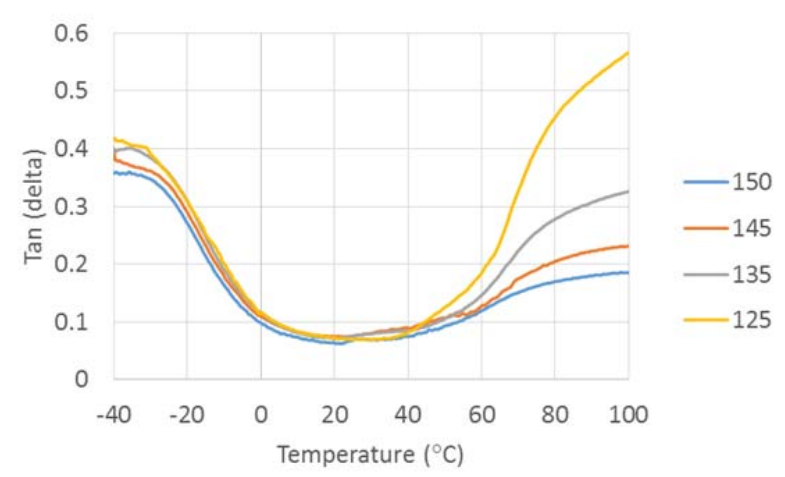

Fig. 2. Measured $\tan (\delta)$ values over temperature range of TC test.

The TC testing was carried out in an environmental chamber. During the test, all mini-modules were periodically removed to conduct I-V measurements at STC condition using a Pasan IIIb solar simulator.

\subsection{Modelling thermomechanical stresses accumulation on solder bonds}

Finite-element analysis (FEA) is employed to simulate thermomechanical strains generated during thermal cycling and to calculate the damage potential on solder joints. A 2D model is developed using COMSOL Multiphysics, which reflects the mini-modules previously described. The inelastic deformation of the solder joints is considered in this work as means of evaluating damage potential and is simulated using Anand's viscoplastic model. ${ }^{32)}$ The model quantifies the isotropic resistance to plastic flow, as defined by the structure characteristics of the solder alloy e.g. grain size, dislocation density etc. This value is denoted as $S$ and is referred to as deformation resistance. Naturally, the value of $S$ evolves with temperature and time as the internal structure of the solder changes. Anand's 
model consists of two coupled differential equations which relates inelastic deformation rate to deformation resistance. The strain rate equation for the Anand model can be written as Eq. (4), where the evolution of $s$ is given by Eqs. (5) and (6).

$$
\dot{\varepsilon}_{\mathrm{p}}=A \cdot \exp \left(-\frac{Q}{R T}\right)\left[\sinh \left(\zeta \frac{\sigma}{S}\right)\right]^{1 / m}
$$

where $\dot{\varepsilon}_{\mathrm{p}}$ is the inelastic strain rate, $A$ the pre-exponential factor, $Q$ the activation energy, $\mathrm{m}$ the strain rate sensitivity, $\zeta$ the stress multiplier, $R$ the gas constant and $T$ the absolute temperature.

$$
\begin{gathered}
\dot{s}=\left\{h_{0}\left|1-\frac{s}{s^{*}}\right|^{a} \cdot \sinh \left(1-\frac{s}{s^{*}}\right)\right\} \cdot \dot{\varepsilon}_{p} ; \quad a>1 \\
s^{*}=\hat{s}\left[\frac{\dot{\varepsilon}_{p}}{A} \exp \left(\frac{Q}{R T}\right)\right]^{n}
\end{gathered}
$$

where $h_{0}$ is the hardening constant, a the strain rate sensitivity of hardening, $s^{*}$ the saturation value of $s, \hat{s}$ the coefficient and $n$ the strain rate sensitivity for the saturation value of deformation resistance. The material parameters required for calculating viscoplastic deformation are $A, Q, \zeta, m, h_{0}, \hat{s}, n, a$ and $s_{0}$. Where $s_{0}$ is the initial deformation resistance value. These material parameters for $60 \mathrm{Sn} 40 \mathrm{~Pb}$ solder alloy are well-defined in the literature ${ }^{33)}$ and are given in Table I below.

Table I. Anand Viscoplastic model parameters for eutectic $60 \mathrm{Sn} 40 \mathrm{~Pb}$ solder alloy.

\begin{tabular}{cc}
\hline Parameter & Value \\
\hline $\mathrm{A}$ & $1.49 \times 10^{7}$ \\
$\mathrm{Q}(\mathrm{j} / \mathrm{mol})$ & 90046 \\
$\zeta$ & 11 \\
$\mathrm{~m}$ & 0.241 \\
$\mathrm{~h}_{0}$ & 2640 \\
$\hat{s}(\mathrm{MPa})$ & 80.42 \\
$\mathrm{n}$ & 2.31 \\
$\mathrm{a}$ & 1.34 \\
$\mathrm{~s}_{0}$ & 56.3 \\
\hline
\end{tabular}

The mini-modules fabricated at Loughborough consist of a single cell soldered using a $60 \mathrm{Sn} 40 \mathrm{~Pb}$ solder alloy and copper-based interconnecting ribbons. Table II summarizes the dimensions of each component, which is used in the FEA model.

Table II. Dimensions of mini-module components used in the model, mm. 


\begin{tabular}{cccc}
\hline Component & Length & Width & Height \\
\hline Cell & 150 & 80 & 0.22 \\
Glass & 200 & 123 & 2.9 \\
Encapsulant & 200 & 123 & 0.8 \\
Backsheet & 200 & 123 & 0.41 \\
Ribbons & $80-145$ & 1.5 & 0.3 \\
Solder & 80 & 1.5 & 0.02 \\
\hline
\end{tabular}

Appropriate material properties must be defined in the model in order to produce appropriate results. For the remaining materials, material properties are either measured or furnished from datasheets of the manufacturers, which are summarized in Table III.

Table III. Material properties of each component used in the model.

\begin{tabular}{ccccc}
\hline Component & CTE $\left(10^{-6} / \mathrm{K}\right)$ & $\begin{array}{c}\text { Young's Modulus } \\
(\mathrm{GPa})\end{array}$ & Poisson's Ratio & Density $\left(\mathrm{g} / \mathrm{cm}^{3}\right)$ \\
\hline Cell & 2.7 & 128 & 0.28 & 2.3 \\
Glass & 8 & 73 & 0.23 & 2.5 \\
Backsheet & 5.04 & 3.5 & 0.29 & 2.5 \\
Ribbons & 17 & 105 & 0.35 & 8.5 \\
\hline
\end{tabular}

\section{Results and discussion}

\subsection{Degradation of performance parameters}

Differences in performance degradation of the mini-modules with EVA of different viscoelastic properties are observed during the extended TC test as shown in Fig. 3, which plots averaged values and standard deviations of the maximum power $\left(\mathrm{P}_{\mathrm{MPP}}\right)$, short circuit current $\left(\mathrm{I}_{\mathrm{SC}}\right)$, open circuit voltage $\left(\mathrm{V}_{\mathrm{OC}}\right)$ and fill factor $(\mathrm{FF})$ for mini-modules with EVA of different viscoelastic properties, respectively.

The mini-modules with EVA cured at $125^{\circ} \mathrm{C}$ (referred to in the following as L125 samples, the same as for L135, L145 and L150 samples) saw the largest $\mathrm{P}_{\mathrm{MPP}}$ degradation of more than $20 \%$ after 400 cycles and about $30 \%$ after 1400 cycles. This is followed by the L135 samples, which experienced around $8 \%$ degradation after 400 cycles and then degraded faster afterwards and saw power losses about 30\% after 1400 cycles. The L145 and L150 samples showed good performance and experienced less than 3\% degradation after 400 cycles and degraded $13 \%$ and $6 \%$, respectively, after 1400 cycles. The mini-modules with EVA of high $\tan \delta$ values, which would exhibit more significant displacement during TC test, showed greater degradation. 
The $\mathrm{I}_{\mathrm{SC}}$ degradation of all mini-modules showed a slight different pattern comparing to the power degradation over time. The L125 samples experienced the largest degradation among all samples showing 5\% loss after 400 cycles and about 10\% after 1400 cycles. All other samples saw minor degradation in $\mathrm{I}_{\mathrm{SC}}$ and did not degrade more than $2 \%$ until 900 cycles. The L135 samples saw about 7\% loss in ISC after 1400 cycles, while the L145 and L150 samples are still stable. The $\mathrm{V}_{\mathrm{OC}}$ remained almost unchanged over time for all mini-modules and the small variations in the result may be due to temperature influences on the measurements. The most significant contribution to the power degradation is seen in the FF, where similar degradation patterns were observed. . The solder bond fatigue which leads to increase in the equivalent series resistance is expected to be a major contributor for the FF losses. In the following it is shown that the fatigue accumulation for different mini-modules and the change of equivalent series resistance obey a good correlation.

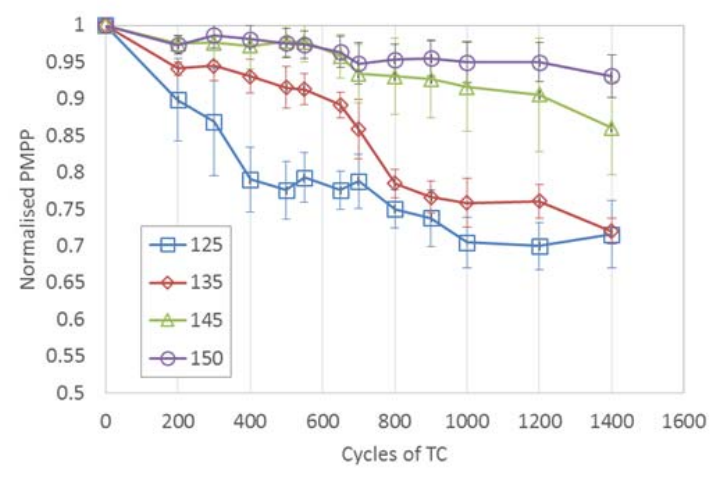

(a)

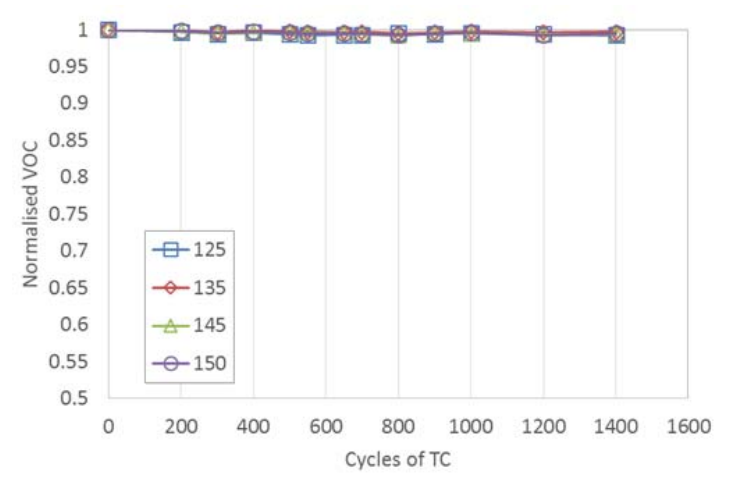

(c)

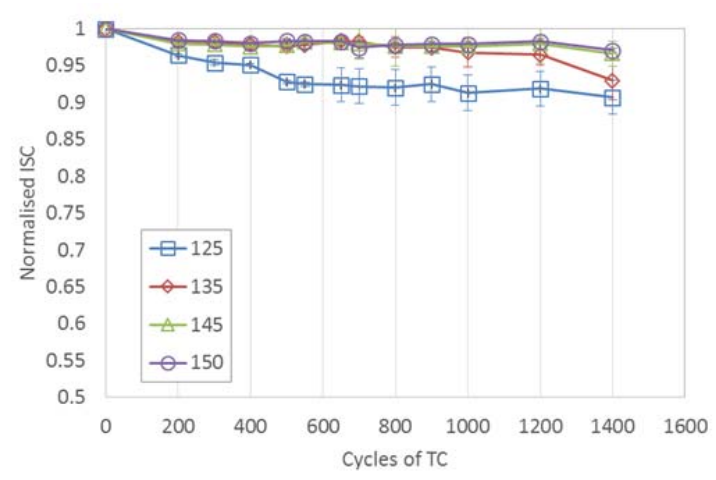

(b)

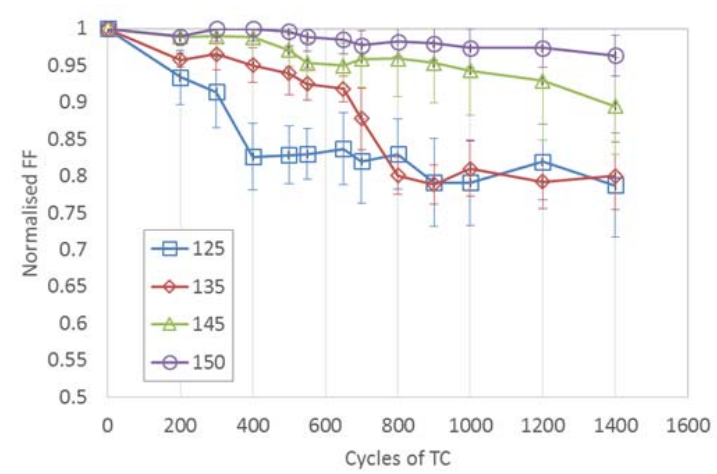

(d)

Fig. 3. $\mathrm{P}_{\mathrm{MPP}}, \mathrm{I}_{\mathrm{SC}}, \mathrm{V}_{\mathrm{OC}}$ and $\mathrm{FF}$ degradation during thermal cycling. 


\subsection{Correlation of thermomechanical fatigue accumulation and series resistance degradation}

Simulations of thermomechanical fatigue accumulation on solder bonds are carried out for L125, L135, L145 and L150 samples. Figure 4 shows both the accumulated damage and cycling temperature for L125 samples. It can be identified that the thermomechanical fatigue accumulated largely during ramping periods. This is characteristic of the behavior of the solder that is explained by the hyperbolic sine term in Anand's model. The damage accumulation is faster when temperature ramps up from 50 to $85^{\circ} \mathrm{C}$, as 1) the solder resistance to deformation is smaller at higher temperature; ${ }^{32)}$ and 2) the loss factor $\tan \delta$ increases with the increasing temperature, which leads to higher energy dissipation and increased displacement. The loss factor decreases, when temperature ramps down. As temperature ramps down below $0^{\circ} \mathrm{C}$ and approaches the lower dwell temperature at $-40^{\circ} \mathrm{C}$, EVA material passes through the glass transition and the loss factor becomes higher again and therefore increasing the strain imposed on solder bonds. This simulation can be applied to all samples including L125, L135, L145 and L150. With EVA of different viscoelastic properties as indicated by the loss factor shown in Fig. 2, according to simulations, the L125 samples see about 40\% more accumulated damage than the L150 samples do.

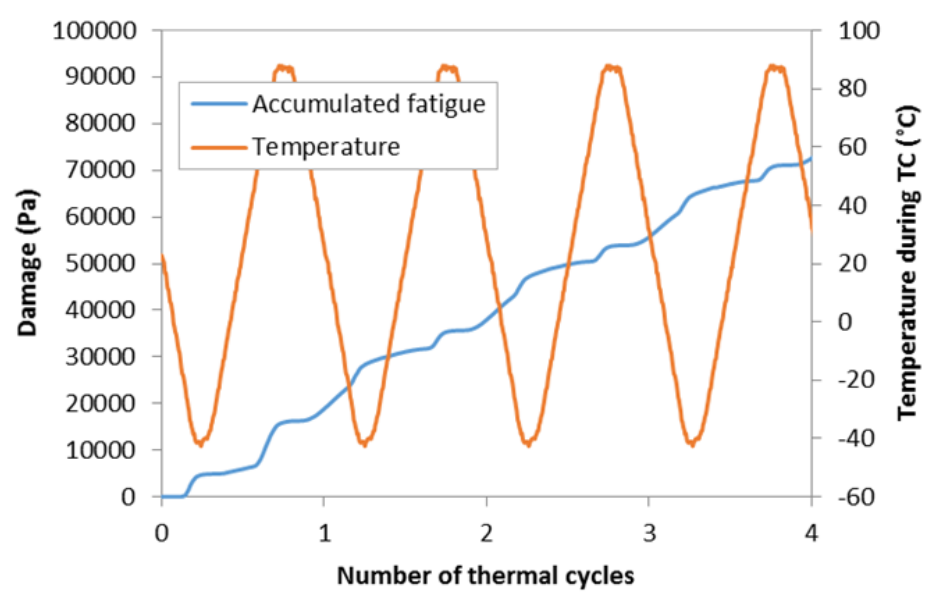

Fig. 4. Simulation of thermomechanical fatigue accumulation during TC test for L125 samples.

The thermomechanical fatigue generated during TC test leads to ageing of solder bonds, which increases the equivalent series resistance $\left(\mathrm{R}_{\mathrm{S}}\right)$. Based on this assumption, a 
correlation between the equivalent series resistance and the estimated fatiguing can be established.

Changes in slopes of I-V curves are evident from the I-V measurements as plotted in Fig. 5 for L125 and L150 samples, respectively. Clear changes in slopes at $\mathrm{V}_{\mathrm{OC}}$ can be observed for the L125 sample, but no changes for the L150 sample. With the comparison analysis of extracted diode model parameters presented in Ref. 3), the equivalent series resistances for all mini-modules over TC test are evaluated. The averaged values and standard deviations of the equivalent series resistance for L125, L135, L145 and L150 samples are plotted in Fig. 6 against TC testing cycles. The L125 samples saw early increases in equivalent $\mathrm{R}_{\mathrm{S}}$, which is followed by the L135 and L145 samples. The equivalent $\mathrm{R}_{\mathrm{S}}$ of L150 samples remained stable after 1400 cycles. The degradation of equivalent $\mathrm{R}_{\mathrm{S}}$ for L125, L135 and L145 samples tend to stabilize after a fast increase. This could be due to the ageing of EVA and other components of the module and their properties, therefore, can change over the course of ageing.

The increase of equivalent $R_{S}$ is observed over time as a result of solder bond degradation and a correlation between the changes in $\mathrm{R}_{S}$ and the thermomechanical fatigue is established and plotted in Fig. 7 for the L125, L135, L145 and L150 samples, respectively. Considering the nonlinear behaviour of solder joints degradation and change of equivalent $\mathrm{R}_{\mathrm{S}}$, which are basically determined by material properties, the damage of thermomechanical stresses on solder joints is estimated by a Coffin-Manson type equation, ${ }^{34)}$ as $A S^{m}$, with $\mathrm{S}$ the generated thermomechanical stress, $\mathrm{A}$ and $\mathrm{m}$ are the constants found through least square regression represent the nonlinear degradation behaviours. Three stages of the degradation can be identified: 1) Initial thermomechanical fatigue accumulation before the increase in $\mathrm{R}_{\mathrm{S}}$. This means there is an induction or initiation phase before rapid degradation takes place on solder bonds. This can be the initiation of crack on solder bonds. 2) Thermomechanical fatigue led deformation of solder joints results in fast increase in $\mathrm{R}_{\mathrm{S}}$. This can be the crack growth. 3) Stabilization of $R_{S}$. The stabilization of $R_{S}$ is not clearly understood and further investigation is required. But it could be explained by the fact that material's resistance to deformation increases with deformation. ${ }^{32)}$ Another factor may be the PV material ages during the test, which minimizes the influences of thermomechanical fatigue on solder joints as well. 

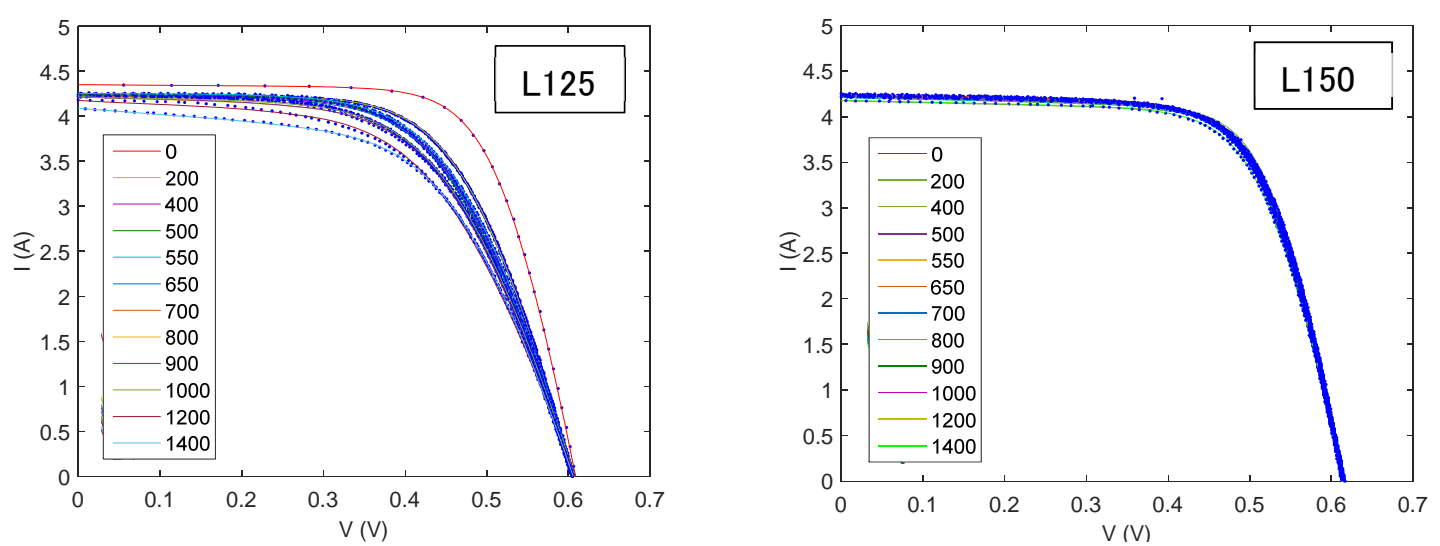

Fig. 5. I-V characteristics after 0-1400 cycles of TC testing for a sample cured at $125^{\circ} \mathrm{C}$ (L125) and a sample cured at $150^{\circ} \mathrm{C}(\mathrm{L} 150)$. Dots are measured I-Vs, while solid lines are fitted I-Vs.

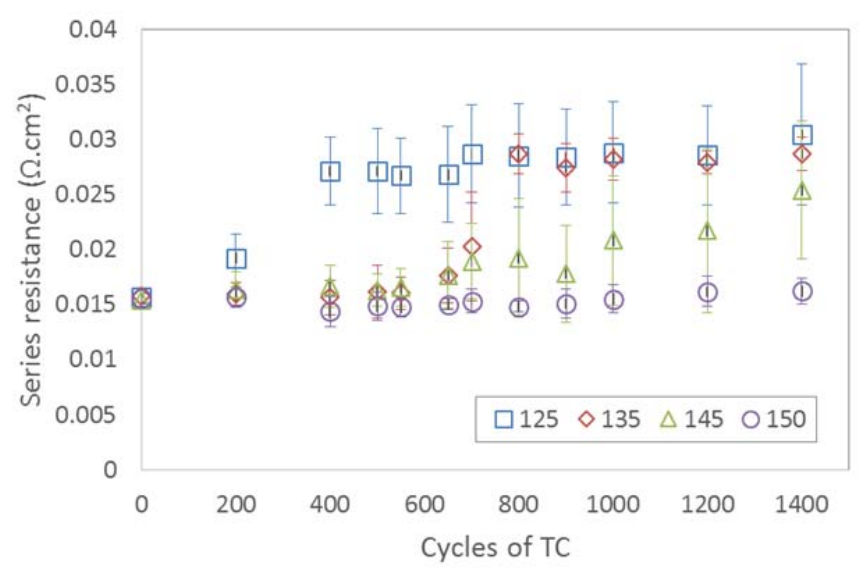

Fig. 6. Series resistance extracted from I-V cures during thermal cycling.

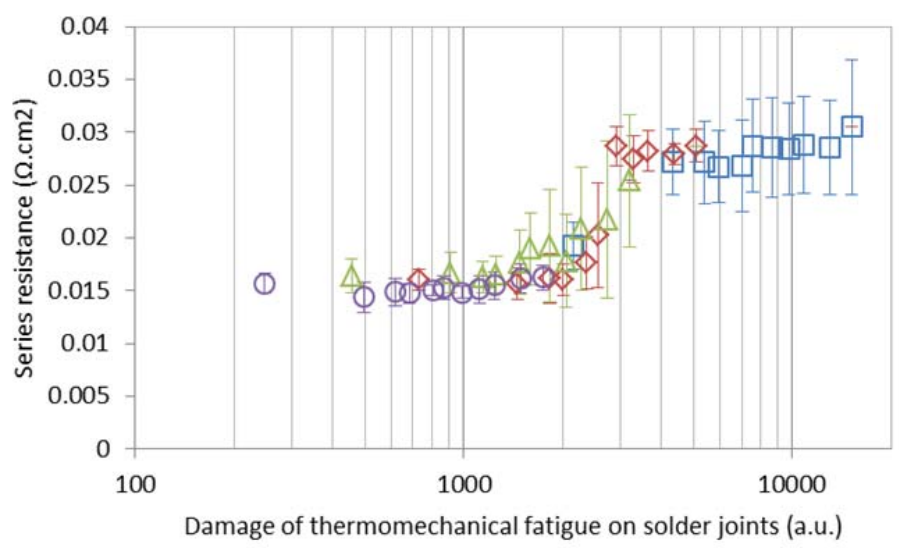

Fig. 7. Correlation between series resistance degradation and thermomechanical fatigue on solder joints. 


\section{Conclusions}

Degradation of solder bonds within a PV module was evaluated for mini-modules with EVA of different viscoelastic properties based on the extracted equivalent series resistance and the simulated accumulation of thermomechanical fatigue. The viscoelastic properties of the EVA have been shown to have a significant impact on the imposed strains of the solder bonds. The mini-modules with EVA cured at lower temperature, which exhibit more significant displacement during thermal cycling test, experienced larger degradation in power. The degradation of power of different mini-modules appears to be due to FF losses, and shows similar curved pattern as the increase in series resistance. Based on this assumption of thermomechanical fatiguing leading to series resistance degradation, the correlation between the accumulation of thermomechanical fatigue and the increase in the equivalent series resistance shows good agreement. 


\section{References}

1) D. C. Jordan, S. R. Kurtz, K. Vansant, and J. Newmiller, Prog. Photovolt: Res. Appl. 24, 978 (2016).

2) D. Wu, J. Zhu, T.R. Betts, and R. Gottschalg, Prog. Photovolt: Res. Appl. 22, 796 (2014).

3) J. Zhu, M. Koehl, S. Hoffmann, K.A. Berger, S. Zamini, I. Bennett, E. Gerritsen, P. Malbranche, P. Pugliatti, A. Di Stefano, F. Aleo, D. Bertani, F. Paletta, F. Roca, G. Graditi, M. Pellegrino, O. Zubillaga, F.J.C. Iranzo, A. Pozza, T. Sample and R. Gottschalg, Prog. Photovolt: Res. Appl., 24, 1346 (2016).

4) J. Zhu, M. Bliss, T.R. Betts, R. Gottschalg, Jpn. J. Appl. Phys. 54, 08KG03 (2015).

5) N. Bogdanski, W. Herrmann, F. Reil, M. Köhl, K.-A. Weiss, M. Heck, Proc. 25th EUPVSEC, 2010, p. 4339.

6) A. Adiyabat, K. Otani, N. Enebish, N. Enkhmaa, Proc. 35th IEEE PVSC, 2010, p. 2656.

7) O.S. Sastry, S. Saurabh, S.K. Shil, P.C. Pant, R. Kumar, A. Kumar, B. Bandopadhyay, Sol. Energy Mater. Sol. Cells 94, 1463 (2010).

8) L.V.B. Machado Neto, E.M.D. Pereira, L.G. Monteiro, E.G. Arreguy, Proc. 22nd EUPVSEC, 2007, p. 2750.

9) S.H.F. de Oliveira, R. Zilles, Prog. Photovolt: Res. Appl. 9, 341 (2001).

10) A. Messaoudi, A.S. Bouazzi, Proc. 23rd EUPVSEC, 2008, p. 3554.

11) J.Y. Ye, T. Reindl, A.G. Aberle, IEEE J. Photovolt. 4, 1288 (2014).

12) D. H. Otth and R. J. Ross, Proc. $29^{\text {th }}$ Inst. of Environmental Science Annual Meeting, 1983, p. 121.

13) J. Coello, F. Cornacchia, J. Muñoz, Proc. 25th EUPVSEC, 2010, p. 4019.

14) D. Berman, S. Biryukov, D. Faiman, Sol. Energy Mater. Sol. Cells 36, 421 (1995).

15) I.M. Saleh, I. Abouhdima, M.B. Gantrari, Proc. 24th EUPVSEC, 2009, p. 3995.

16) L. Abenante, F. De Lia, S. Castello, Proc. 25th EUPVSEC, 2010, p. 4023.

17) D.C. Jordan, B. Sekulic, B. Marion, S.R. Kurtz, IEEE J. Photovolt. 5, 744 (2015).

18) S. Suzuki, T. Doi, A. Masuda, T. Tanahashi, Jpn. J. Appl. Phys. 57, 02 CE05 (2018).

19) D.C. Jordan, T.J. Silverman, J.H. Wohlgemuth, S.R. Kurtz, and K.T. VanSant, Prog. Photovolt: Res. Appl. 25 [4], 318 (2017).

20) D.C. Jordan, T.J. Silverman, B. Sekulic, S.R. Kurtz, Proc. 32nd EUPVSEC, 2016, p. 1678. 
21) S. Chattopadhyay, et al., All-India survey of PV module reliability: 2016 (NCPRE \& NISE, 2017).

22) T. Friesen, D. Chianese, A. Realini, G. Friesen, E. Burà, A. Virtuani, D. Strepparava, R. Meoli, Proc. 27th EUPVSEC, 2012, p. 3125.

23) A. Bradley, B. Hamzavy, W. Gambogi, Proc. SPIE, 2014, p. 917901.

24) J. Singh, J. Belmont, G. TamizhMani, Proc. 39th IEEE PVSC, 2013, p. 3270.

25) C. R. Osterwald, J. Pruett, S. Rummel, A. Anderberg, and L. Ottoson, Proc. Nat. Center Photovolt. Program Rev. Meeting, 2000, p. 65.

26) J. H. Wohlgemuth, D. W. Cunningham, P. Monus, J. Miller, and A. Nguyen, Proc. 4th World Conf. Photovolt. Energy Convers., 2006, p. 2050.

27) W. Herrmann, N. Bogdanski, F. Reil, M. Köhl, K.-A. Weiss, M. Assmus, M. Heck, Proc. SPIE Reliab. Photovolt. Cells, Modules, Compon., Syst. Conf., 2010, p. 777301.

28) A. F. Dethlefsen, Proc. Photovolt. Module Reliab. Workshop, 2011, p. 1002.

29) N. Bosco, T. J. Silverman, and S. Kurtz, IEEE J. Photovolt. 6 [6], p. 1407 (2016).

30) M. Owen-Bellini, D. Montiel-Chicharro, J. Zhu, T. R. Betts and R. Gottschalg, IEEE J. Photovolt. 8 [1], 183 (2018).

31) Crystalline Silicon Terrestrial Photovoltaic (PV) Modules-Design Qualification and Type Approval, IEC Std. 61215, 2016.

32) L. Anand, Int. J. Plast., 1 [3], p. 213 (1985).

33) Z. N. Cheng, G. Z. Wang, L. Chen, J. Wilde, and K. Becker, Solder. Surf. Mt. Technol. 12 [2], p. 31 (2000).

34) L.F. Coffin, Trans. ASME 76, p. 931 (1954). 